\title{
Change in Daily Life Behaviors and Depression: Within-Person and Between-Person Associations
}

Citation for published version (APA):

Snippe, E., Simons, C. J. P., Hartmann, J. A., Menne-Lothmann, C., Kramer, I., Booij, S. H., Viechtbauer, W., Delespaul, P., Myin-Germeys, I., \& Wichers, M. (2016). Change in Daily Life Behaviors and Depression: Within-Person and Between-Person Associations. Health Psychology, 35(5), 433-441. https://doi.org/10.1037/hea0000312

Document status and date:

Published: 01/05/2016

DOI:

10.1037/hea0000312

Document Version:

Publisher's PDF, also known as Version of record

Document license:

Taverne

Please check the document version of this publication:

- A submitted manuscript is the version of the article upon submission and before peer-review. There can be important differences between the submitted version and the official published version of record.

People interested in the research are advised to contact the author for the final version of the publication, or visit the DOI to the publisher's website.

- The final author version and the galley proof are versions of the publication after peer review.

- The final published version features the final layout of the paper including the volume, issue and page numbers.

Link to publication

\footnotetext{
General rights Owners
rights.

- You may freely distribute the URL identifying the publication in the public portal. please follow below link for the End User Agreement:

www.umlib.nl/taverne-license

Take down policy

If you believe that this document breaches copyright please contact us at:

repository@maastrichtuniversity.nl

providing details and we will investigate your claim.
}

Copyright and moral rights for the publications made accessible in the public portal are retained by the authors and/or other copyright owners and it is a condition of accessing publications that users recognise and abide by the legal requirements associated with these

- Users may download and print one copy of any publication from the public portal for the purpose of private study or research.

- You may not further distribute the material or use it for any profit-making activity or commercial gain

If the publication is distributed under the terms of Article $25 \mathrm{fa}$ of the Dutch Copyright Act, indicated by the "Taverne" license above, 


\title{
Change in Daily Life Behaviors and Depression: Within-Person and Between-Person Associations
}

\author{
Evelien Snippe \\ Maastricht University and University of Groningen \\ Jessica A. Hartmann
University of Melbourne \\ Ingrid Kramer \\ Maastricht University and GGzE, Institute of Mental Health \\ Care Eindhoven and De Kempen
Wolfgang Viechtbauer, Philippe Delespaul, and Inez Myin-Germeys
Maastricht University

\author{
Claudia J. P. Simons \\ Care Eindhoven and De Kempen
Claudia Menne-Lothmann
Maastricht University \\ Sanne H. Booij \\ University of Groningen
}

Maastricht University and GGzE, Institute of Mental Health

\author{
Marieke Wichers \\ Maastricht University and University of Groningen
}

\begin{abstract}
Objective: This study examined associations between daily physical, sedentary, social, and leisure behaviors and depressive symptoms (a) at a macrolevel, over the course of an Experience Sampling (ESM) self-monitoring intervention, and (b) at a microlevel, by examining daily within-person associations. Second, we examined the effects of the ESM self-monitoring intervention on these daily life behaviors. Methods: Individuals with a diagnosis of depression $(N=102)$ receiving pharmacological treatment were randomized to 1 of 2 six-week ESM intervention conditions or a control condition. Physical, sedentary, social, and leisure behaviors as well as depressive symptoms were assessed prospectively in every-day life at baseline, postintervention, and during the ESM interventions. Results: Change in physical activity and talking from baseline to postintervention was associated with change in depressive symptoms from baseline to postintervention. Within-person daily fluctuations in talking, physical activity, doing nothing/resting, and being alone predicted end-of-day depressive symptoms over and above depressive symptoms at the previous day. The ESM interventions contributed to change in talking, doing nothing/resting, and being alone over time in comparison with the control group. The analyses revealed individual differences in the amount of behavioral change over time and in the within-subject associations between daily behaviors and depressive symptoms. Conclusions: The findings suggest that physical, sedentary, and social behaviors have affective implications for daily mental
\end{abstract}

This article was published Online First December 21, 2015.

Evelien Snippe, Department of Psychiatry \& Psychology, School for Mental Health and Neuroscience, Maastricht University, and Interdisciplinary Center Psychopathology and Emotion Regulation, University of Groningen, University Medical Center Groningen; Claudia J. P. Simons, Department of Psychiatry \& Psychology, School for Mental Health and Neuroscience, Maastricht University, and GGzE, Institute of Mental Health Care Eindhoven and De Kempen; Jessica A. Hartmann, Orygen, the National Centre of Excellence in Youth Mental Health, University of Melbourne; Claudia Menne-Lothmann, Department of Psychiatry \& Psychology, School for Mental Health and Neuroscience, Maastricht University; Ingrid Kramer, Department of Psychiatry \& Psychology, School for Mental Health and Neuroscience, Maastricht University, and GGzE, Institute of Mental Health Care Eindhoven and De Kempen; Sanne H. Booij, Interdisciplinary Center Psychopathology and Emotion Regulation, University of Groningen, University Medical Center Groningen; Wolfgang Viechtbauer, Philippe Delespaul, and Inez Myin-Germeys, Department of Psychiatry \& Psychology, School for Mental Health and Neuroscience, Maastricht University; Marieke Wichers, Department of Psychiatry \&
Psychology, School for Mental Health and Neuroscience, Maastricht University, and Interdisciplinary Center Psychopathology and Emotion regulation, University of Groningen, University Medical Center Groningen.

This study was supported by the Dutch Health Research Council, (ZON-MW Grants 171001002 and 91501003), an Aspasia Grant (NWO; to M. Wichers), and a VICI Grant (NWO Grant 91812607; to P. de Jonge). The ESM assessments were performed with the PsyMate device. This tool was developed under the auspices of the Maastricht University technology transfer office, which was partially supported by unrestricted grants from Servier and Janssen-Cilag. The authors thank all patients for participating and the collaborating mental health centers for their support in recruiting patients. They also thank W. Beuken and T. Driessen for administrative support, and P. Höhn, K. Akkermans, R. Diederen, K. Gielen, M. Hendriks, and E. Pols for support in data acquisition.

Correspondence concerning this article should be addressed to Evelien Snippe, Interdisciplinary Center Psychopathology and Emotion Regulation (ICPE), University of Groningen, University Medical Center Groningen, P.O. Box 30.001, 9700 RB Groningen, The Netherlands. E-mail: e.snippe01@umcg.nl 
health of individuals with depression. Self-monitoring using ESM may be a useful add-on tool to achieve behavioral change and to gain personalized insight in behaviors that improve daily depressive symptoms.

Keywords: ambulatory monitoring, depression, motor activity, sedentary lifestyle, social behavior

Depression is a common mental health condition that may interfere with functioning in daily life. Individuals with depression are more likely to withdraw from social interaction (Hopko \& Mullane, 2008) as well as physical activity (Burton et al., 2013; Teychenne, Ball, \& Salmon, 2008) and they are more likely to show sedentary behavior (i.e., activity approximately at the resting metabolic rate; Barge-Schaapveld, Nicolson, van der Hoop, \& DeVries, 1995; Teychenne, Ball, \& Salmon, 2010). Psychological interventions have therefore focused on reducing the passiveness that comes along with depression using behavioral activation strategies. Interventions including behavioral activation, such as behavior therapy and cognitive behavior therapy, have indeed been shown effective in reducing depressive symptoms (Cuijpers, van Straten, \& Warmerdam, 2007).

However, the above-mentioned cross-sectional studies and intervention studies do not make clear whether changing social, physical, and sedentary behaviors in daily life indeed contribute to recovery from depression and to daily mental health. One way to gain more knowledge about this is to examine whether a change in daily life behaviors is associated with a change in depression over the course of an intervention. To do so in an ecologically valid and reliable way, it is valuable to take repeated prospective assessments of behaviors in everyday life using real-time assessments (i.e., ambulatory or momentary assessments; aan het Rot, Hogenelst, \& Schoevers, 2012; Csikszentmihalyi \& Larson, 1987). One previous study using such an approach indicated that patients who recover from depression after antidepressant treatment can be distinguished from patients who do not recover by the amount of increase in time spent on household activities and decrease in time spent on passive leisure activities (Barge-Schaapveld et al., 1995).

More recently, it has been acknowledged that studying withinperson associations provides more insight in the causal direction of actual processes taking place within individuals in daily life and individual differences (Hamaker, 2012; Kanning, Ebner-Priemer, \& Schlicht, 2013; Molenaar \& Campbell, 2009), as opposed to studies examining changes from baseline to postintervention using only two time points. By examining whether within-person fluctuations in daily life behavior predict mental health on a next moment in time, one could make inferences on whether certain patterns of behavior have an impact on how individuals feel later in time (Kanning et al., 2013; Kraemer, Wilson, Fairburn, \& Agras, 2002).

Several studies examined associations between daily life behaviors and affective states using repeated daily assessments. These studies were able to show prospective associations between physical activity (Bossmann, Kanning, Koudela-Hamila, Hey, \& Ebner-Priemer, 2013; Feuerhahn, Sonnentag, \& Woll, 2014; Gauvin, Rejeski, \& Norris, 1996; Mata et al., 2012; Schwerdtfeger, Eberhardt, \& Chmitorz, 2008; Steptoe, Kimbell, \& Basford, 1998; Wichers et al., 2012) and social interaction (Brown, Strauman, Barrantes-Vidal, Silvia, \& Kwapil, 2011; Clark \& Watson, 1988; LePage \& Crowther, 2010; Sandstrom \& Dunn, 2014; Watson,
Clark, Mcintyre, \& Hamaker, 1992) on the one hand and positive or negative affective states on the other hand. Yet, the above studies either did not include individuals with depression or did not examine the impact of fluctuations in daily life behaviors on depressive symptoms while properly disaggregating within-person from between-person effects (Curran \& Bauer, 2011), except for one study on physical activity (Rosmalen, Wenting, Roest, de Jonge, \& Bos, 2012). It is important to separate within-person from between-person associations because these are not necessarily similar (Hamaker, 2012; Molenaar, 2004). That is, the question if individuals are more depressed when they are more alone than others (between-subjects association) differs from the question if individuals are more depressed when they are more alone than usual (within-subject association) (Curran \& Bauer, 2011). Therefore, it remains unclear whether within-person changes in social, physical, and sedentary behaviors affect the experience of depressive symptoms in the daily life of individuals with depression.

The current study may fill the gaps in the literature by examining the associations between daily life behaviors (i.e., physical, sedentary, leisure, and social behaviors) and depression at (a) the microlevel, by examining within-person prospective associations, and (b) at the macrolevel, over the course of an intervention that may foster behavioral change. To our knowledge, no study, to date, has performed such an investigation in individuals with depression. This study is unique in that it prospectively assesses a broad range of daily life behaviors and depressive symptoms before, during, and after an intervention and assesses both withinperson temporal associations and associations between change from baseline to postintervention.

The current study is embedded in a randomized controlled trial on the effects of a 6-week mobile Experience Sampling Method (ESM) self-monitoring intervention, with and without personalized feedback, as an add-on treatment for individuals diagnosed with depression who currently receive antidepressant medication. The primary results of the trial have been published previously (Kramer et al., 2014). Self-monitoring may lead to behavioral change by raising awareness of adaptive and dysfunctional behavior, which increases the availability of adequate information to make more adaptive responses (Prochaska \& DiClemente, 1982). Self-monitoring has also been shown to induce change in behavior, such as tics (Thomas, Abrams, \& Johnson, 1971) and snack-eating (Maas, Hietbrink, Rinck, \& Keijsers, 2013). Likewise, ESM selfmonitoring of present-moment behaviors and affect may stimulate depressed individuals to become aware of and to engage more in behaviors that generate positive emotions such as physical, leisure, and social activities. Such behavioral change increases the chance of positive reinforcement and positive emotions, which may counteract depressive symptoms (Lewinsohn \& Graf, 1973; Wichers et al., 2010).

The first aim of the current study is to examine whether changes in physical, sedentary, leisure, and social behaviors are associated with changes in depressive symptoms. We investigate this first by 
examining the associations between change in behaviors and depressive symptoms over the course of the ESM interventions (i.e., from baseline to postintervention). Second, we examine the associations at the day-level by investigating within-person temporal associations between behavior during the day and symptoms at the end of the day, while controlling for depressive symptoms of the previous day. We hypothesized that decreases in depressive symptoms would be predicted by decreases in sedentary behaviors and increases in physical, leisure, and social behaviors. The second aim is to examine whether ESM self-monitoring interventions are associated with change in these behaviors over time and in comparison with a control condition. We hypothesized that ESM self-monitoring of present-moment activities and mood would stimulate depressed individuals to engage in less sedentary behaviors and more in physical, leisure, and social behaviors over time and in comparison with the control condition.

\section{Method}

\section{Participants}

A full description of the design, procedures, flow of participants, feasibility, and primary outcomes of the current multicenter trial have been published elsewhere (Hartmann et al., 2015; Kramer et al., 2014). In short, participants were 102 individuals with major depressive disorder who received antidepressants or mood stabilizers. Other inclusion criteria were Hamilton Depression Rating Scale (HDRS; Hamilton, 1960) score $\geq 8$, age 18-65, adequate vision, sufficient ability to read and write Dutch, no current or lifetime diagnosis of nonaffective psychotic disorder, and no (hypo)manic or mixed episode within the past month.

Participants were recruited between January 2010 and February 2012 at mental health care facilities, at local hospitals, at a university, and by means of advertisements in the south of the Netherlands. Eligibility was assessed by means of a telephone interview and a full on-site screening. The Structured Clinical Interview for Diagnostic and Statistical Manual of Mental Disorders, fourth edition (DSM-IV) Axis I Disorders (SCID-I) and the HDRS were administered by trained researchers and research assistants to verify the presence of major depressive disorders.

\section{Study Procedures}

All allocated participants were asked to complete five days of Experience Sampling (ESM) assessments before randomization (baseline) and one week after the intervention period (postintervention). The ESM procedure was concordant with those of other studies (Myin-Germeys, van Os, Schwartz, Stone, \& Delespaul, 2001; Wichers et al., 2007). Participants were prompted to respond 10 times a day at semirandom moments (in each of ten 90-min time blocks between 07:30 a.m. and 10:30 p.m.) to questions about momentary affective states, behavior, and contexts using an electronic ESM device (PsyMate) (Myin-Germeys, Birchwood, \& Kwapil, 2011).

Participants were randomized to an experimental group ( $n=$ 33), a pseudoexperimental group $(n=36)$, and a control group $(n=33)$. Randomization (allocation ratio $1: 1: 1)$ was stratified by duration of antidepressant pharmacotherapy (longer vs. shorter than eight weeks of antidepressant use before study entry) and by current psychotherapy attendance (yes/no). The randomization sequence was generated in blocks of six (www.random.org). The randomization code was drawn from sealed envelopes by an independent research assistant. Because of the resource constraints and the fact that participants necessarily were not blind to allocation, interviewers were also not blinded to allocation.

\section{Interventions}

Participants in the experimental group and the pseudoexperimental group engaged in ESM self-monitoring of momentary affective states, behavior, and contexts 10 times a day, three days a week over a period of six weeks (intervention period). In the experimental group, participants and their mental health care providers also received weekly personalized feedback on changes in affect and daily life behavioral patterns as well as their interrelations. For example, feedback was provided on the contexts and activities that were associated with higher levels of momentary positive affect. The pseudoexperimental group received weekly HDRS interviews instead of the personalized feedback to prevent an effect of a difference in contact duration with the researchers. The control group received care as usual only (i.e., antidepressant medication) and did not have contact with the researchers during the 6-week intervention period. A more elaborate description of the intervention groups is provided elsewhere (Hartmann et al., 2015; Kramer et al., 2014).

\section{Measures}

ESM assessments. Participants recorded their social company and what they were doing just before the last beep using ESM questions with different answer categories. Participants could choose one or two of these categories. Of all possible response options, we made a selection of those behaviors that have most often been described as important both for positive emotions and for the process of recovery from depression. We measured the occurrence ( 0 or 1$)$ of sedentary behavior (nothing/resting), social behaviors (talking and being alone), and leisure behaviors (passive leisure activities and active leisure activities). As a measure of physical activity, participants rated the question "Since the last beep, I have engaged in physical activity" on a Likert-scale ranging from 1 (not at all) to 7 (very much).

End-of-day reports. The depression subscale of the Symptom Check List-90-Revised (SCL-90-R; Derogatis, 1994) was used to assess daily depressive symptoms. The SCL-90-R was used as this subclinical measure is more sensitive to small changes in symptoms than clinical rating scales (Derogatis, 1994). Participants were asked to complete the scale at the end of each ESM day in the two ESM intervention groups. Each item was rated on a 5-point Likert scale ranging from 1 (not at all) to 5 (extremely). The composite SCL-90-R end-of-day mean depression score can range from 0 to 5 .

Depressive symptoms at baseline and postintervention. Depressive symptomatology was assessed with the 17-item Hamilton Depression Rating Scale (HDRS) (Hamilton, 1960) at baseline, one week after, and two weeks after the intervention period. The HDRS scores at 2-weeks follow-up were used as a measure of postintervention depressive symptoms to be able to impute the missing values of four participants using the HDRS scores at 
1-week follow-up. The total HDRS score can range from 0 to 52 . The internal, retest, and interrater reliability of the HDRS semistructured interview have been shown to be good (Bagby, Ryder, Schuller, \& Marshall, 2004).

\section{Statistical Analyses}

Because ESM assessments (level one) are nested within individuals (level two), multilevel analyses were conducted. First, we examined whether a change from baseline to postintervention in daily life behaviors is associated with a baseline to postintervention change in depressive symptoms (as measured with the HDRS). This concerns a between-subjects analysis as it examines whether individuals who show a larger change in daily life behaviors than others also show a large change in depressive symptoms than others. Only patients receiving one of the ESM selfmonitoring interventions (the pseudoexperimental group and the experimental group) were included as they are expected to show a change in depressive symptoms. Logistic multilevel analyses were performed for the dichotomous behaviors. In each analysis one of the daily behaviors was included as the dependent variable. The models included baseline-post change in depressive symptoms, a variable denoting time ( $0=$ baseline and $1=$ postintervention $)$, as well as the interaction between time and change in depressive symptoms as fixed effects, and included a random intercept for participants as well as a random slope for time.

Second, within-person associations were examined between daily behaviors during the day and end-of-the-day depressive symptoms (measured with the SCL-90-R depression subscale) over the course of the 6-week self-monitoring interventions using multilevel autoregressive modeling (Rovine \& Walls, 2006). For the dichotomous behaviors, the number of times that individuals reported to engage in a certain type of behavior during the day was divided by the total number of completed ESM assessments per day. For physical activity, the mean level of physical activity during the day was computed. Logistic multilevel modeling was conducted for the dichotomous behaviors. End-of-day depressive symptoms were modeled as the dependent variable. The timevarying predictors were first grand-mean centered and then person-mean centered to disaggregate within-subject effects from between-subjects effects (Bolger \& Laurenceau, 2013; Curran \& Bauer, 2011). Time in days, the person mean of the examined behavior, the deviation from the person mean of the examined behavior at $(t)$, as well as the deviation from the person mean of end-of-day depressive symptoms at $(t-1$; to remove autocorrelation from the series) were included as fixed effects. All models included a random intercept for participants. A random slope for the time-varying predictor variables was included when it improved model fit. Both the random effect variances from the multilevel models and Best Linear Unbiased Predictions (BLUPs; Bayesian predictions of the individual deviations from the fixed effects based on the multilevel models; Rabe-Hesketh \& Skrondal, 2008) were used as indications of heterogeneity in the withinsubject effects.

Third, it was examined whether the 6-week ESM interventions were associated with change in daily behaviors in two ways. (a) The change in daily behaviors from baseline to postintervention was compared between the ESM intervention groups (combined and separately) and the control group. Logistic multilevel model- ing was conducted for the dichotomous behaviors. The models included time ( $0=$ baseline, $1=$ postintervention $)$, a dummy variable for treatment allocation, and the interaction between time and treatment allocation as fixed effects. (b) The presence of linear growth in the daily behaviors over time was tested, as well as individual differences in this growth over the course of the 6-week ESM interventions (the control group was not included in these analyses). The analyses included one of the behaviors during the ESM interventions as the dependent variable, time in weeks (0-5) as a fixed effect, a random intercept for participants, and a random slope for time. The random effect variances of the slope for time are indicators of the individual differences in the amount of behavioral change over time.

For all analyses, models with different (co)variance structures for the random effects (level-2 variances) and residuals (level-1 variance) were specified and the model with the best fit according to the Akaike Information Criterion (AIC) was chosen as the final model. All analyses were carried out using STATA (version 13.1).

\section{Results}

\section{Descriptives}

The means and percentages of the reported daily life behaviors and depressive symptoms at baseline and postintervention are presented in Table 1. There were no significant differences in these measures between the intervention groups and control group at baseline. About half of the sample was female $(54.2 \%)$ and was living with a partner/own family $(52.0 \%)$. The majority of participants was unemployed $(65.7 \%)$ and did not have a comorbid $D S M-I V$ Axis I disorder (60.8\%). The mean age of the participants was $48.0(S D=10.2)$. Sixty-nine individuals were allocated to the ESM intervention groups. Of these individuals, 59 completed the 6-week ESM intervention. At postintervention, ESM assessments of 85 participants were available and HDRS assessments of 91 participants were available. Level of education was significantly lower in participants without HDRS assessments at postinvention $(D=1.06, S E=0.50, t=2.11, p=.04)$. No differences in the other demographic or clinical characteristics were observed in the participants who did not complete the postintervention assessments. In total, participants completed 16,595 valid ESM entries. On average, participants completed 39.7 of 50 ESM assessments during the 5-day ESM periods (baseline and postintervention assessments) and 23.7 of 30 ESM assessments during the 3-day intervention periods (Hartmann et al., 2015). The number of assessments ranged between 4605 and 4612 for the analyses on associations between baseline-post changes in behavior and depressive symptoms. The number of assessments ranged between 7,495 and 7,509 for the analyses on the effects of the ESM interventions on behavioral change in comparison with the control group.

\section{Between-Person Associations: Baseline-Post Change in Behaviors and Depressive Symptoms}

Change in depressive symptoms (HDRS) after the 6-week ESM intervention was associated with change in some of the daily life behaviors. Patients who showed a larger reduction in depressive symptoms from baseline to postintervention than others showed on 
Table 1

Daily Life Behaviors and Depressive Symptoms at Baseline and Postintervention

\begin{tabular}{llcc}
\hline & & \multicolumn{2}{c}{ Percentage/mean $(S D)$} \\
\cline { 3 - 4 } Variable & $\begin{array}{c}\text { Treatment } \\
\text { allocation }\end{array}$ & $\begin{array}{c}\text { Baseline } \\
(N=102)\end{array}$ & $\begin{array}{c}\text { Postintervention } \\
(N=85)\end{array}$ \\
\hline Nothing/resting & Pseudo & 52.40 & 45.44 \\
& Experimental & 53.72 & 48.16 \\
Leisure active & Control & 58.60 & 63.01 \\
& Pseudo & 12.86 & 11.87 \\
Leisure passive & Experimental & 11.14 & 9.90 \\
& Control & 10.59 & 12.72 \\
Talking & Pseudo & 23.90 & 24.89 \\
& Experimental & 26.11 & 30.41 \\
Being alone & Control & 24.01 & 22.41 \\
& Pseudo & 19.84 & 30.20 \\
Physical & Experimental & 21.75 & 23.67 \\
activity & Control & 21.82 & 18.10 \\
& Pseudo & 48.71 & 44.64 \\
& Experimental & 45.80 & 43.28 \\
& Control & 40.42 & 48.78 \\
Depression & Pseudo & $2.67(1.86)$ & $2.94(1.94)$ \\
(HDRS) & Experimental & $2.66(1.94)$ & $2.53(1.73)$ \\
& Control & $2.66(1.84)$ & $2.55(1.81)$ \\
& & & $N=91$ \\
\hline
\end{tabular}

Note. The Hamilton Depression Rating Scale-17 (HDRS) was assessed before and two weeks after the Experience Sampling Method (ESM) intervention. Missing postintervention HDRS scores of 4 participants were imputed with one-week follow-up scores. Missing postintervention ESM records of four participants were imputed with ESM data of the sixth week of the ESM self-monitoring period. The daily life behaviors add up to more than $100 \%$ because participants could engage in more than one behavior at a time.

average a larger baseline to postintervention increase in talking $(B=-0.06, S E=0.02, Z=-2.27, p=.02)$ and physical activity $(B=-0.06, S E=0.03, Z=-2.18, p=.03)$. The reduction from baseline to postintervention in depressive symptoms was not associated with the change in the other daily behaviors, including doing nothing/resting $(B=0.02, S E=0.02, Z=0.88, p=.38)$, active leisure activities $(B<0.01, S E=0.04, Z=0.03, p=.98)$, passive leisure activities $(B=-0.02, S E=0.03, Z=-0.57, p=$ $.57)$, and being alone ( $B=0.02, S E=0.03, Z=0.64, p=.53)$.

\section{Within-Person Associations Between Fluctuations in Behaviors and End-of-Day Depression}

Within-person fluctuations in most of the daily life behaviors predicted end-of-day depressive symptoms (SCL-90-R), while controlling for depressive symptoms at the end of the previous day, over the course of the 6-week ESM interventions (see Table 2). On average, individuals reported lower levels of depressive symptoms at the end of the day when they had engaged more often in physical activity or talking and when they had engaged less often in doing nothing/resting or being alone during the day. The random effects indicated significant between-subjects variability in the effect of doing nothing/resting and physical activity (see Table 2). Based on these random effects, it is estimated that the effect of doing nothing/resting on end-of-day depressive symptoms ranges between -0.09 and 0.60 and that the effect of physical activity ranges between -0.13 and 0.03 in approximately $95 \%$ of the population. ${ }^{1}$ The Best Linear Unbiased Predictions (BLUPs; RabeHesketh \& Skrondal, 2008) indicated a smaller range of betweensubjects variability (see Figures 1 and 2). The associations between active leisure activities as well as passive leisure activities during the day and depressive symptoms at the end of the day did not reach significance.

\section{Effect of the Interventions on Baseline-Post Change in Behaviors Compared With the Control Group}

Participants in the two ESM self-monitoring interventions showed on average a significantly higher increase in talking, decrease in doing nothing/resting, and decrease in being alone from baseline to postintervention in comparison with the control group (see Table 3). No significant difference in average change was observed in physical activity, passive leisure activities, and active leisure activities in the two intervention groups in comparison with the control group. Similar results were obtained when the two ESM self-monitoring interventions were compared to the control group separately (see Table 3). However, the effects of the experimental group on talking and being alone in comparison with the control group did not reach significance any more ( $p=$ .07 , respectively $p=.08$ )

\section{Growth in Behaviors Over the Course of the 6-Week ESM Interventions}

On average, there was a significant linear trend in several of the behaviors over the course of the 6-week ESM interventions. There was an average decrease in the log-odds of doing nothing/resting of 0.07 per week $(B=-0.07, S E=0.03, Z=-2.67, p<.01)$, an average increase in the log-odds of passive leisure activities of 0.04 per week $(B=0.04, S E=0.02, Z=2.12, p=.03)$, and a nonsignificant trend toward increases in the log-odds of talking of 0.04 per week $(B=0.04, S E=0.02, Z=1.76, p=.08)$. The random effect variances indicated significant differences between individuals in the direction and steepness of the growth over time in the daily behaviors, and also in the daily behaviors that did not show an average change over time. The random effect variances indicated that the amount of change per week ranged between -0.40 and 0.26 for doing nothing/resting, between -0.15 and 0.23 for passive leisure activities, between -0.16 and 0.24 for talking, between -0.41 and 0.33 for being alone, between -0.21 and 0.14 for active leisure activities, and between -0.31 and 0.37 for physical activity in approximately $95 \%$ of the population.

\section{Discussion}

This study is the first to examine within-person associations between daily fluctuations in a broad range of daily life behaviors and end-of-day depressive symptoms in individuals with depression by taking ESM assessments over the course of an intervention. These within-subject analyses revealed more subtle and im-

\footnotetext{
${ }^{1}$ These intervals are prediction intervals based on the random effect variances and not confidence intervals for the betas.
} 
Table 2

Within-Person Associations Between Fluctuations in Daily Behaviors and End-of-Day Depression

\begin{tabular}{|c|c|c|c|c|c|c|}
\hline \multirow[b]{2}{*}{ Predictors } & \multicolumn{6}{|c|}{ Coefficient $(S E)$} \\
\hline & Nothing/resting & Leisure active & Leisure passive & Talking & Being alone & Physical activity \\
\hline \multicolumn{7}{|l|}{ Fixed effects } \\
\hline Depressive symptoms $t-1$ & $.48(.04)^{* * *}$ & $.44(.04)^{* *}$ & $.45(.04)^{* * *}$ & $.46(.04)^{* *}$ & $.44(.04)^{* * *}$ & $.46(.04)^{* *}$ \\
\hline Behavior: person mean & $.58(.41)$ & $.76(1.17)$ & $-.98(.65)-1.00$ & $-1.17(57)^{*}$ & $.80(.33)^{*}$ & $-.07(.10)$ \\
\hline Behavior: deviation from person mean & $.25(.09)^{* * *}$ & $-.25(.13)$ & $.12(.10)$ & $-.31(.09)^{* * *}$ & $.34(.07)^{* * *}$ & $-.05(.02)^{*}$ \\
\hline Time in weeks & $-.02(.01)^{*}$ & $-.03(.01)^{* * *}$ & $-.03(.01)^{*}$ & $-.02(.01)^{*}$ & $-.02(.01)$ & $-.02(.01)^{*}$ \\
\hline \multicolumn{7}{|l|}{ Random effects (in $S D s$ ) } \\
\hline Subjects & $.69(.07)^{* * *}$ & $.69(.07)^{* * *}$ & $.68(.07)^{* * *}$ & $.67(.06)^{* * *}$ & $.66(.06)^{* * *}$ & $.70(.07)^{* * *}$ \\
\hline Behavior: deviation from person mean & $.17(.20)^{* * *}$ & Omitted & Omitted & Omitted & Omitted & $.04(.06)^{*}$ \\
\hline Time in weeks & $.04(.02)^{* * *}$ & $.04(.02)^{* * *}$ & $.04(.02)^{* * *}$ & $.04(.02)^{* * *}$ & $.04(.01)^{* * *}$ & $.04(.02)^{* * *}$ \\
\hline N/observations & $64 / 525$ & $64 / 525$ & $64 / 525$ & $64 / 525$ & $64 / 525$ & $64 / 525$ \\
\hline
\end{tabular}

Note. Dependent variable is end-of-day depressive symptoms in all models. Behavior represents any of the behaviors mentioned in the columns. Random effects were omitted when $<.01$ and reduced model fit according to the AIC.

${ }^{*} p<.05$, two-tailed. ${ }^{* *} p<.01$, two-tailed.

mediate temporal effects of physical, sedentary, and social behaviors on end-of-day depressive symptoms. Also, we were able to show that ESM self-monitoring interventions contribute to change in daily life behaviors of individuals with depression.

Changing physical, sedentary, and social behaviors may be important for individuals with depression as is evidenced by our finding that within-person fluctuations in these types of behaviors predict end-of-day depressive symptoms over and above depressive symptoms at the previous day. On average, depressed individuals had lower levels of end-of-day depressive symptoms when they engaged more in talking or physical activities and when they engaged less in doing nothing/resting or being alone than usual during the day. The findings on the daily benefits of social behavior correspond and extend the findings of Brown and colleagues (Brown et al., 2011) that showed that depressed individuals have lower levels of negative affect (NA) and higher levels of positive affect (PA) when they were with close social partners at a previous moment.

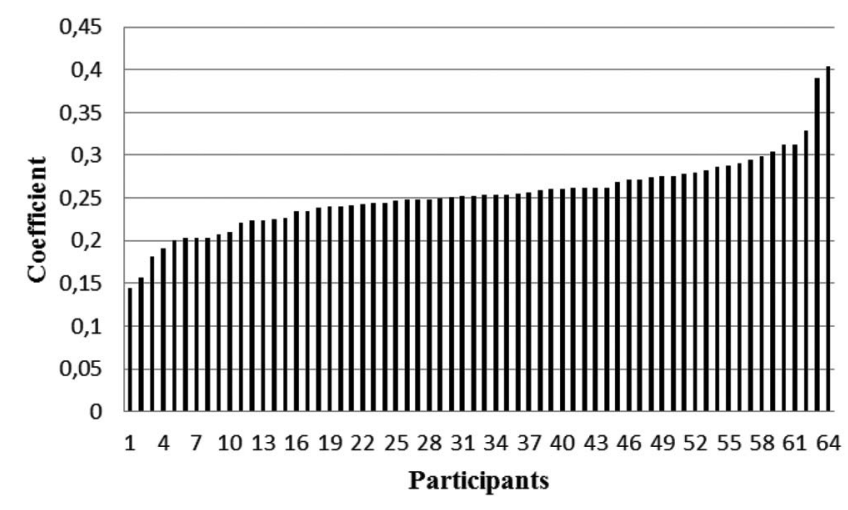

Figure 1. Predicted individual effects of doing nothing/resting on endof-day depressive symptoms. Individual coefficients were predicted by Best Linear Unbiased Predictions (BLUPs; Rabe-Hesketh \& Skrondal, 2008) based on the random effects of the multilevel model presented in Table 2. Bars represent the predicted coefficients of the association between doing nothing/resting and end-of-day depressive symptoms per individual.
The current study also explains previous inconsistent findings between studies on the impact of physical activity on NA in individuals with depression (Mata et al., 2012; Steptoe et al., 1998; Wichers et al., 2012). The random effect variances indicated that individuals differed in the extent to which self-reported physical activity and doing nothing/resting were associated with end-of-day depressive symptoms. A few previous studies also found individual differences in the impact of physical activity on affect (von Haaren et al., 2013) and depressive symptoms (Rosmalen et al., 2012). Future studies should reveal whether clinical or demographic characteristics (e.g., age, presence of a chronic somatic disease, coping style, average level of physical activity and depression) can explain these individual differences. To gain insight into this, future studies may use individual time-series analyses to examine for which individuals the impact of physical activity and doing nothing/resting is more profound. Furthermore, the fact that such individual differences exist also urges the need for personalized interventions in psychiatry. That is, not all depressed individuals may benefit equally from similar interventions. Individual

\section{Participants}

14710131619222528313437404346495255586164

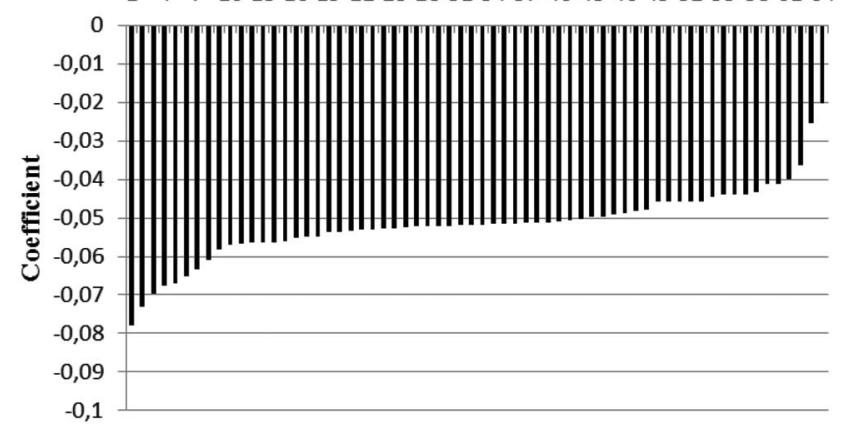

Figure 2. Predicted individual effects of physical activity on end-of-day depressive symptoms. Individual coefficients were predicted by Best Linear Unbiased Predictions (BLUPs; Rabe-Hesketh \& Skrondal, 2008) based on the random effects of the multilevel model presented in Table 2. Bars represent the predicted coefficients of the association between physical activity and end-of-day depressive symptoms per individual. 
Table 3

Baseline to Postintervention Change in Behaviors in ESM Intervention Groups in Comparison With the Control Group

\begin{tabular}{|c|c|c|c|c|c|c|c|c|}
\hline \multirow{2}{*}{$\begin{array}{l}\text { Dependent } \\
\text { variable }\end{array}$} & \multirow{2}{*}{$\begin{array}{l}\text { Treatment } \\
\text { allocation }\end{array}$} & \multicolumn{3}{|c|}{ Time $\times$ Treatment } & \multirow{2}{*}{$\begin{array}{l}\text { Treatment } \\
\text { allocation }\end{array}$} & \multicolumn{3}{|c|}{ Time $\times$ Treatment } \\
\hline & & $B(S E)$ & $Z$ & $P$ & & $B(S E)$ & $Z$ & $P$ \\
\hline \multirow[t]{2}{*}{ Nothing/resting } & \multirow[t]{2}{*}{ ESM interv. } & \multirow[t]{2}{*}{$-.68(.22)$} & \multirow[t]{2}{*}{-3.16} & \multirow[t]{2}{*}{$<.01$} & Pseudo & $-.80(.24)$ & -3.33 & $<.01$ \\
\hline & & & & & Experimental & $-.54(.25)$ & -2.21 & .03 \\
\hline \multirow[t]{2}{*}{ Leisure active } & \multirow[t]{2}{*}{ ESM interv. } & \multirow[t]{2}{*}{$-.22(.32)$} & \multirow[t]{2}{*}{-.68} & \multirow[t]{2}{*}{.49} & Pseudo & $-.20(.36)$ & -.56 & .57 \\
\hline & & & & & Experimental & $-.24(.37)$ & -.64 & .52 \\
\hline \multirow[t]{2}{*}{ Leisure passive } & \multirow[t]{2}{*}{ ESM interv. } & \multirow[t]{2}{*}{$.11(.23)$} & \multirow[t]{2}{*}{.50} & \multirow[t]{2}{*}{.62} & Pseudo & $-.02(.25)$ & -.06 & .95 \\
\hline & & & & & Experimental & $.26(.26)$ & .99 & .32 \\
\hline \multirow[t]{2}{*}{ Talking } & \multirow[t]{2}{*}{ ESM interv. } & \multirow[t]{2}{*}{$.74(.24)$} & \multirow[t]{2}{*}{3.14} & \multirow[t]{2}{*}{$<.01$} & Pseudo & $.96(.26)$ & 3.73 & $<.01$ \\
\hline & & & & & Experimental & $.49(.27)$ & 1.83 & .07 \\
\hline \multirow[t]{2}{*}{ Being alone } & \multirow[t]{2}{*}{ ESM interv. } & \multirow[t]{2}{*}{$-.59(.24)$} & \multirow[t]{2}{*}{-2.46} & \multirow[t]{2}{*}{.01} & Pseudo & $-.69(.27)$ & -2.56 & .01 \\
\hline & & & & & Experimental & $-.48(.28)$ & -1.73 & .08 \\
\hline \multirow[t]{2}{*}{ Physical activity } & \multirow[t]{2}{*}{ ESM interv. } & \multirow[t]{2}{*}{$.24(.22)$} & \multirow[t]{2}{*}{1.11} & \multirow[t]{2}{*}{.27} & Pseudo & $.42(.24)$ & 1.73 & .08 \\
\hline & & & & & Experimental & $.04(.25)$ & .16 & .87 \\
\hline
\end{tabular}

Note. Time $=(0=$ baseline, $1=$ postintervention $)$, treatment $(0=$ control group, $1=$ the experimental group and/or the pseudo-experimental group $)$, ESM interv. = the experimental and the pseudo-experimental group. In the left column, the control group is compared with the ESM interventions together. In the right column, the control group is compared with either the experimental group or the pseudo-experimental group.

time-series analyses may be helpful to reveal if low levels of physical activity elicit depressive symptoms in a specific individual and may reveal which daily life behaviors predict lower levels of depressive feelings. This knowledge may improve clinical decision making and may help to predict which patient would benefit from what type of intervention.

By studying both micro within-person temporal associations and change from baseline to postintervention, we could show that within-person fluctuations in daily life behaviors were more robust predictors of depression than between-person differences in behavioral change over time. Behavioral change from baseline to post-ESM intervention was for most behaviors not associated with between-person differences in the amount of depressive symptom change from baseline to post-ESM intervention. Only patients who showed a larger change from baseline to postintervention in talking and physical activity showed a larger baseline to postintervention reduction in depressive symptoms compared to others, although these effects were rather small.

The discrepant findings might be explained by the fact that associations between changes from baseline to postintervention may not capture the subtle processes taking place within individuals and individual differences, as these are between-person associations (Hamaker, 2012; Molenaar, 2004). Analyses of associations occurring within individuals might be more valuable as these take into consideration that daily behaviors and depressive symptoms fluctuate from day to day and that there may be individual differences. Another possibility is that individuals differed in the type of behavior that they changed over the course of the ESM interventions, as indicated by the strong heterogeneity in the linear trends observed in the behaviors over time. This might have cancelled out the associations between changes in daily life behaviors and depressive symptoms from baseline to postintervention.

This study also shows that ESM self-monitoring interventions, with and without personal feedback, may stimulate individuals with depression to engage more in social behaviors and less in sedentary behaviors. The patterns of behavioral change were comparable between ESM self-monitoring without feedback (pseudo- experimental group) and ESM self-monitoring with feedback on behavior and positive emotions (experimental group). The observed effects of the ESM interventions on the amount of doing nothing/resting, talking, and being alone are in accordance with theories posing that increasing awareness of dysfunctional and adaptive behavior induces self-regulatory behavior (Kanfer, 1970). These findings are promising with regard to the potential of using experience sampling techniques as therapeutic interventions. ESM assessments and self-monitoring may be used as an add-on tool in addition to existing behavioral activation strategies; both to reveal relevant behavioral patterns to intervene on and to promote awareness of and change in behavioral patterns. An advantage of mobile self-monitoring is that mobile devices and mobile-phone applications have become readily available to make these strategies easy in use and affordable.

Finally, the results illustrate the heterogeneity in the extent to which individuals show change in different behaviors over time during the ESM self-monitoring interventions. These individual differences might also explain why the ESM interventions did not have an average effect on physical activity, active leisure activities, and passive leisure activities. The average effect of ESM self-monitoring on these daily life behaviors may be cancelled out because individuals differed in the type of behaviors that they changed upon ESM self-monitoring.

This study has several notable methodological strengths, including real-time assessments of a broad range of daily behaviors and depressive symptoms before, during, and after the ESM interventions, and the examination of prospective long-term associations, more subtle within-person associations, as well as individual differences. Yet, there are also several limitations to be mentioned. If patients had performed ESM self-monitoring during all days of the 6-week intervention period, we would have been able to examine true within-subject associations and individual differences more reliably by using replicated single-subject time-series analyses. However, such an intensive sampling schedule would be a high burden for patients and the random effect variances obtained with the current design do give an indication of the degree of betweensubjects heterogeneity. Furthermore, the use of accelerometers in 
addition to ESM self-reports may have resulted in a more accurate measurement of physical activity (Kanning et al., 2013). In addition, the possibility cannot be fully excluded that the behavioral change observed in the ESM intervention groups is a result of the study procedures that might have had an activating effect, including weekly face-to-face contact with one of the researchers. Finally, it should be noted that the temporal direction of the betweenperson associations between changes from baseline to postintervention cannot be inferred. This does not hold for the within-person analyses, where the temporal order of the associations between changes in behavior and in depressive symptoms has been taken into account.

In conclusion, this study highlights that adjusting one's daily life activities may have important implications for the emotional wellbeing of individuals with depression. The study also shows that individuals may differ in the extent to which physical activity and sedentary behaviors affect their depressive symptoms and the type of behavioral change that they show upon self-monitoring. Mobile ESM self-monitoring may be a useful add-on tool to realize daily life behavioral change and to gain personalized insight in which daily activities improve one's daily depressive symptoms.

\section{References}

aan het Rot, M., Hogenelst, K., \& Schoevers, R. A. (2012). Mood disorders in everyday life: A systematic review of experience sampling and ecological momentary assessment studies. Clinical Psychology Review, 32, 510-523. http://dx.doi.org/10.1016/j.cpr.2012.05.007

Bagby, R. M., Ryder, A. G., Schuller, D. R., \& Marshall, M. B. (2004). The Hamilton Depression Rating Scale: Has the gold standard become a lead weight? The American Journal of Psychiatry, 161, 2163-2177. http:// dx.doi.org/10.1176/appi.ajp.161.12.2163

Barge-Schaapveld, D. Q., Nicolson, N. A., van der Hoop, R. G., \& De Vries, M. W. (1995). Changes in daily life experience associated with clinical improvement in depression. Journal of Affective Disorders, 34, 139-154. http://dx.doi.org/10.1016/0165-0327(95)00012-C

Bolger, N., \& Laurenceau, J. (2013). Intensive longitudinal methods: An introduction to diary and experience sampling research. New York, NY: Guilford Press.

Bossmann, T., Kanning, M., Koudela-Hamila, S., Hey, S., \& EbnerPriemer, U. (2013). The association between short periods of everyday life activities and affective states: A replication study using ambulatory assessment. Frontiers in Psychology, 4, 102. http://dx.doi.org/10.3389/ fpsyg.2013.00102

Brown, L. H., Strauman, T., Barrantes-Vidal, N., Silvia, P. J., \& Kwapil, T. R. (2011). An experience-sampling study of depressive symptoms and their social context. Journal of Nervous and Mental Disease, 199, 403-409. http://dx.doi.org/10.1097/NMD.0b013e31821cd24b

Burton, C., McKinstry, B., Szentagotai Tătar, A., Serrano-Blanco, A., Pagliari, C., \& Wolters, M. (2013). Activity monitoring in patients with depression: A systematic review. Journal of Affective Disorders, 145, 21-28. http://dx.doi.org/10.1016/j.jad.2012.07.001

Clark, L. A., \& Watson, D. (1988). Mood and the mundane: Relations between daily life events and self-reported mood. Journal of Personality and Social Psychology, 54, 296-308. http://dx.doi.org/10.1037/00223514.54.2.296

Csikszentmihalyi, M., \& Larson, R. (1987). Validity and reliability of the experience-sampling method. Journal of Nervous and Mental Disease, 175, 526-536. http://dx.doi.org/10.1097/00005053-198709000-00004

Cuijpers, P., van Straten, A., \& Warmerdam, L. (2007). Behavioral activation treatments of depression: A meta-analysis. Clinical Psychology Review, 27, 318-326. http://dx.doi.org/10.1016/j.cpr.2006.11.001
Curran, P. J., \& Bauer, D. J. (2011). The disaggregation of within-person and between-person effects in longitudinal models of change. Annual Review of Psychology, 62, 583-619. http://dx.doi.org/10.1146/annurev .psych.093008.100356

Derogatis, L. R. (1994). Symptom checklist-90-R. administration, scoring, and procedures manual (3rd ed.). Minneapolis, MN: National Computer Systems.

Feuerhahn, N., Sonnentag, S., \& Woll, A. (2014). Exercise after work, psychological mediators, and affect: A day-level study. European Journal of Work and Organizational Psychology, 23, 62-79. http://dx.doi .org/10.1080/1359432X.2012.709965

Gauvin, L., Rejeski, W. J., \& Norris, J. L. (1996). A naturalistic study of the impact of acute physical activity on feeling states and affect in women. Health Psychology, 15, 391-397. http://dx.doi.org/10.1037/ 0278-6133.15.5.391

Hamaker, E. L. (2012). Why researchers should think 'within-person': A paradigmatic rationale. In M. R. Mehl \& T. S. Conner (Eds.), Handbook of research methods for studying daily life (pp. 43-61). New York, NY: Guilford Press.

Hamilton, M. (1960). A rating scale for depression. Journal of Neurology, Neurosurgery, \& Psychiatry, 23, 56-62. http://dx.doi.org/10.1136/jnnp .23.1.56

Hartmann, J. A., Wichers, M., Menne-Lothmann, C., Kramer, I., Viechtbauer, W., Peeters, F., . . Simons, C. J. P. (2015). Experience samplingbased personalized feedback and positive affect: A randomized controlled trial in depressed patients. PLOS ONE, 10, e0128095. http://dx .doi.org/10.1371/journal.pone.0128095

Hopko, D. R., \& Mullane, C. M. (2008). Exploring the relation of depression and overt behavior with daily diaries. Behaviour Research and Therapy, 46, 1085-1089. http://dx.doi.org/10.1016/j.brat.2008.05.002

Kanfer, F. H. (1970). Self-monitoring: Methodological limitations and clinical applications. Journal of Consulting and Clinical Psychology, 35, 148-152. http://dx.doi.org/10.1037/h0029874

Kanning, M. K., Ebner-Priemer, U. W., \& Schlicht, W. M. (2013). How to investigate within-subject associations between physical activity and momentary affective states in everyday life: A position statement based on a literature overview. Frontiers in Psychology, 4, 187. http://dx.doi .org/10.3389/fpsyg.2013.00187

Kraemer, H. C., Wilson, G. T., Fairburn, C. G., \& Agras, W. S. (2002). Mediators and moderators of treatment effects in randomized clinical trials. Archives of General Psychiatry, 59, 877-883. http://dx.doi.org/ 10.1001/archpsyc.59.10.877

Kramer, I., Simons, C. J. P., Hartmann, J. A., Menne-Lothmann, C., Viechtbauer, W., Peeters, F., . . . Wichers, M. (2014). A therapeutic application of the experience sampling method in the treatment of depression: A randomized controlled trial. World Psychiatry; Official Journal of the World Psychiatric Association (WPA), 13, 68-77. http:// dx.doi.org/10.1002/wps.20090

LePage, M. L., \& Crowther, J. H. (2010). The effects of exercise on body satisfaction and affect. Body Image, 7, 124-130. http://dx.doi.org/10 .1016/j.bodyim.2009.12.002

Lewinsohn, P. M., \& Graf, M. (1973). Pleasant activities and depression. Journal of Consulting and Clinical Psychology, 41, 261-268. http://dx .doi.org/10.1037/h0035142

Maas, J., Hietbrink, L., Rinck, M., \& Keijsers, G. P. J. (2013). Changing automatic behavior through self-monitoring: Does overt change also imply implicit change? Journal of Behavior Therapy and Experimental Psychiatry, 44, 279-284. http://dx.doi.org/10.1016/j.jbtep.2012.12.002

Mata, J., Thompson, R. J., Jaeggi, S. M., Buschkuehl, M., Jonides, J., \& Gotlib, I. H. (2012). Walk on the bright side: Physical activity and affect in major depressive disorder. Journal of Abnormal Psychology, 121, 297-308. http://dx.doi.org/10.1037/a0023533

Molenaar, P. C. M. (2004). A manifesto on psychology as idiographic science: Bringing the person back into scientific psychology, this time 
forever. Measurement: Interdisciplinary Research and Perspectives, 2, 201-218. http://dx.doi.org/10.1207/s15366359mea0204_1

Molenaar, P. C. M., \& Campbell, C. G. (2009). The new person-specific paradigm in psychology. Current Directions in Psychological Science, 18, 112-117. http://dx.doi.org/10.1111/j.1467-8721.2009.01619.x

Myin-Germeys, I., Birchwood, M., \& Kwapil, T. (2011). From environment to therapy in psychosis: A real-world momentary assessment approach. Schizophrenia Bulletin, 37, 244-247. http://dx.doi.org/10 $.1093 /$ schbul/sbq164

Myin-Germeys, I., van Os, J., Schwartz, J. E., Stone, A. A., \& Delespaul, P. A. (2001). Emotional reactivity to daily life stress in psychosis. Archives of General Psychiatry, 58, 1137-1144. http://dx.doi.org/10 .1001/archpsyc.58.12.1137

Prochaska, J. O., \& DiClemente, C. C. (1982). Transtheoretical therapy: Toward a more integrative model of change. Psychotherapy: Theory, Research, \& Practice, 19, 276-288. http://dx.doi.org/10.1037/h0088437

Rabe-Hesketh, S., \& Skrondal, A. (2008). Multilevel and longitudinal modeling using stata (2nd ed.). College Station, TX: Stata press.

Rosmalen, J. G. M., Wenting, A. M. G., Roest, A. M., de Jonge, P., \& Bos, E. H. (2012). Revealing causal heterogeneity using time series analysis of ambulatory assessments: Application to the association between depression and physical activity after myocardial infarction. Psychosomatic Medicine, 74, 377-386. http://dx.doi.org/10.1097/PSY $.0 \mathrm{~b} 013 \mathrm{e} 3182545 \mathrm{~d} 47$

Rovine, M. J., \& Walls, T. A. (2006). Multilevel autoregressive modeling of interindividual differences in the stability of a process. In T. A. Walls \& J. L. Schafer (Eds.), Models for intensive longitudinal data (pp. 124-147). New York, NY: Oxford University Press. http://dx.doi.org/ 10.1093/acprof:oso/9780195173444.003.0006

Sandstrom, G. M., \& Dunn, E. W. (2014). Social interactions and well-being: The surprising power of weak ties. Personality and Social Psychology Bulletin, 40, 910-922. http://dx.doi.org/10.1177/ 0146167214529799

Schwerdtfeger, A., Eberhardt, R., \& Chmitorz, A. (2008). Gibt es einen zusammenhang zwischen bewegungsaktivität und psychischem befinden im alltag? eine methodenillustration zum ambulanten monitoring in der gesundheitspsychologie [Is there a correlation between everyday-life physical activity and psychological well-being? A methodological study using ambulatory monitoring]. Zeitschrift für Gesundheitspsychologie, 16, 2-11. http://dx.doi.org/10.1026/0943-8149.16.1.2
Steptoe, A., Kimbell, J., \& Basford, P. (1998). Exercise and the experience and appraisal of daily stressors: A naturalistic study. Journal of Behavioral Medicine, 21, 363-374. http://dx.doi.org/10.1023/A 1018778730309

Teychenne, M., Ball, K., \& Salmon, J. (2008). Physical activity and likelihood of depression in adults: A review. Preventive Medicine, 46, 397-411. http://dx.doi.org/10.1016/j.ypmed.2008.01.009

Teychenne, M., Ball, K., \& Salmon, J. (2010). Sedentary behavior and depression among adults: A review. International Journal of Behavioral Medicine, 17, 246-254. http://dx.doi.org/10.1007/s12529-010-9075-z

Thomas, E. J., Abrams, K. S., \& Johnson, J. B. (1971). Self-monitoring and reciprocal inhibition in the modification of multiple tics of Gilles de la Torette's syndrome. Journal of Behavior Therapy and Experimental Psychiatry, 2, 159-171. http://dx.doi.org/10.1016/00057916(71)90054-1

von Haaren, B., Loeffler, S. N., Haertel, S., Anastasopoulou, P., Stumpp, J., Hey, S., \& Boes, K. (2013). Characteristics of the activity-affect association in inactive people: An ambulatory assessment study in daily life. Frontiers in Psychology, 4, 163. http://dx.doi.org/10.3389/fpsyg 2013.00163

Watson, D., Clark, L. A., McIntyre, C. W., \& Hamaker, S. (1992). Affect, personality, and social activity. Journal of Personality and Social Psychology, 63, 1011-1025. http://dx.doi.org/10.1037/0022-3514.63.6.1011

Wichers, M. C., Myin-Germeys, I., Jacobs, N., Peeters, F., Kenis, G. Derom, C., . . . van Os, J. (2007). Evidence that moment-to-moment variation in positive emotions buffer genetic risk for depression: A momentary assessment twin study. Acta Psychiatrica Scandinavica, 115, 451-457. http://dx.doi.org/10.1111/j.1600-0447.2006.00924.x

Wichers, M., Peeters, F., Geschwind, N., Jacobs, N., Simons, C. J. P., Derom, C., . . . van Os, J. (2010). Unveiling patterns of affective responses in daily life may improve outcome prediction in depression: A momentary assessment study. Journal of Affective Disorders, 124(1-2), 191-195. http://dx.doi.org/10.1016/j.jad.2009.11.010

Wichers, M., Peeters, F., Rutten, B. P. F., Jacobs, N., Derom, C., Thiery, E., .. van Os, J. (2012). A time-lagged momentary assessment study on daily life physical activity and affect. Health Psychology, 31, 135-144. http://dx.doi.org/10.1037/a0025688

Received April 21, 2015

Revision received August 21, 2015 Accepted September 19, 2015 